\title{
Micro Arc Oxidation of Al-4Si, Al-4Mn and Al-4Mg Binary Alloys
}

\author{
Z.C. Oter, A.E. Gulec, Y. Gencer, M. Tarakci* \\ Gebze Institute of Technology, Department of Materials Science and Engineering, 41400 Gebze, Kocaeli, Turkey
}

\begin{abstract}
Binary synthetic aluminum alloys Al-M ( $\mathrm{M}=\mathrm{Mg}, \mathrm{Mn}, \mathrm{Si})$ containing 4 at.\% alloying elements as substrate materials were prepared under controlled vacuum/argon atmosphere. The substrates were coated by micro arc oxidation (MAO) method for 120 minutes in aqueous alkaline electrolyte using the same electrical parameters. The phase constituents, chemical composition, surface roughness and the microstructure of the coatings were characterized by XRD, profilometry and SEM-EDS. The average coating thicknesses are $127 \mu \mathrm{m}, 91 \mu \mathrm{m}$ and $78 \mu \mathrm{m}$ on Al-4Mn, Al-4Mg and Al-4Si alloys, respectively. All MAO coatings were composed of mullite $\left(3 \mathrm{Al}_{2} \mathrm{O}_{3} \cdot 2 \mathrm{SiO}_{2}\right)$ and $\gamma-\mathrm{Al}_{2} \mathrm{O}_{3}$ phases. In addition to these phases, $\alpha-\mathrm{Al}_{2} \mathrm{O}_{3}$ phase, in the form of precipitates, was detected in coatings on $\mathrm{Al}-4 \mathrm{Mn}$ and $\mathrm{Al}-4 \mathrm{Mg}$ alloys. The presence of $\mathrm{Si}, \mathrm{Mn}$ and $\mathrm{Mg}$ was detected in the coatings, depending of the chemical content of the substrate alloys.
\end{abstract}

DOI: $10.12693 /$ APhysPolA.127.1331

PACS: 81.15.-z, 81.05.Bx

\section{Introduction}

Due to the increase of the demand for durable light and recyclable materials, aluminum alloys are commonly used as engineering materials in a wide range of areas such as metal forming, construction, automotive, textile, aerospace and electronics industries, owing to their outstanding properties such as high specific strength, toughness, recyclability, ductility and corrosion resistance [13]. However extensive applications of aluminum alloys are limited by their low hardness, poor tribological properties and low corrosion resistance in some environments. Many techniques have been investigated to enhance these restricted properties by producing ceramic coatings on metallic components.

Anodic oxidation is one of the widely applied coating methods to improve surface properties of aluminum alloys $[4,5]$. Acidic electrolytes used for this method are not eco friendly and coatings have relatively low thickness and hardness [6].

Microarc oxidation (MAO) is a plasma enhanced electrochemical surface modification method carried out in eco-friendly aqueous alkaline electrolytes. With this method, well adhered and relatively thick ceramic coatings with high surface hardness, wear and corrosion resistance can be produced on light metals such as $\mathrm{Al}, \mathrm{Mg}$, and $\mathrm{Ti}$ at room temperatures [7-12]. Properties of MAO coatings strongly depend on process parameters such as applied voltage, current density, process time, temperature and chemical composition of electrolyte and substrate [13]. Effects of electrical process parameters, process time and electrolyte composition on MAO of $\mathrm{Al}$ alloys were extensively investigated in the literature [14].

* corresponding author; e-mail: mtarakci@gyte.edu.tr
Although there are several studies investigating the effects of substrate composition indirectly by choosing different commercial aluminum alloys as substrates, only a few systematic studies were carried out to reveal individual effects of $\mathrm{Al}$ alloying elements. Gencer et al. investigated the specific effect of Sn on the coatings' properties by preparing MAO coatings on binary Al-Sn alloys with different Sn contents [15]. Gencer and Gulec investigated the effects of increasing $\mathrm{Zn}$ content on properties of MAO coatings produced on binary Al-Zn alloys [16]. Tarakci investigated the effects of $\mathrm{Mg}$ as an alloying element on MAO coatings produced on Al alloys [3]. All these studies showed that properties of MAO coatings such as microhardness, thickness, surface roughness, phase composition and microstructure are strongly affected by presence and amount of alloying elements in binary Al alloys.

Silicon, magnesium and manganese are amongst the main alloying elements used in aluminum alloys. This study was aimed to reveal the comparative effects of the same amount of these alloying elements on properties of MAO coatings. So, the synthetic binary Al4X $(\mathrm{X}=\mathrm{Si}, \mathrm{Mn}, \mathrm{Mg})$ alloys were prepared as substrate materials, coated by MAO method. The thickness, surface roughness, phase composition and microstructure of MAO the coatings formed on Al alloys with the same amount (4 at.\%) of Si, Mn, and Mg in the substrate were characterized and compared.

\section{Experimental}

Pure aluminum (99.96\%), pure manganese (99.9\%), pure silicon $(99.9 \%)$ and pure magnesium (99.9\%) were used to prepare binary $\mathrm{Al}-4 \mathrm{Mn}, \mathrm{Al}-4 \mathrm{Si}, \mathrm{Al}-4 \mathrm{Mg}$ alloys containing 4 at.\% Mn, Si, Mg, respectively. All alloys were prepared by casting in water cooled copper mold under controlled atmosphere. The ingots were sliced to obtain substrates with $25 \mathrm{~mm} \times 50 \mathrm{~mm} \times 4 \mathrm{~mm}$ dimensions. Before the MAO process, plate-shaped substrates 
were ground using $80-1200$ girt $\mathrm{SiC}$ paper, polished using 3-1 $\mu \mathrm{m}$ alumina solution and ultrasonically cleaned in ethanol for 5 min. Veeco Dektak 8 profilometer was utilized to measure the surface roughness of uncoated samples. An electrolyte for MAO process was prepared by dissolving of $12 \mathrm{~g} / 1 \mathrm{Na}_{2} \mathrm{SiO}_{3}$ and $2 \mathrm{~g} / 1 \mathrm{KOH}$ in distilled water. The process was carried out in MAO equipment with $\mathrm{AC}$ power supply. The samples were coated for the duration of $120 \mathrm{~min}$, the electrical parameters and the temperature of the electrolyte were kept constant during all processes. The coated samples were rinsed in distilled water and dried using ethanol under warm air. Phase analysis of coated samples were carried out using Rigaku D-MAX 2200 X-ray diffractometer $(40 \mathrm{~kW}, 40 \mathrm{~mA})$ with a $\mathrm{Cu} \mathrm{K}_{\alpha}$ radiation, over a $2 \theta$ range from $15^{\circ}$ to $90^{\circ}$. The surface roughness of the MAO coated alloys was measured using Veeco Dektak 8 profilometer with the same parameter of bare substrates. Samples were sliced into two pieces for further characterization. One apiece from each sample was cold molded to reveal coating crosssections. The surface and cross sectional microstructures of the coatings were examined by Philips XL 30 scanning electron microscope (SEM). Chemical compositions of coatings were determined using SEM-EDS.

\section{Results and discussion}

Figure 1 shows XRD patterns of MAO-coated Al-4Mn, $\mathrm{Al}-4 \mathrm{Mg}$ and $\mathrm{Al}-4 \mathrm{Si}$ alloys. It can be seen that Mullite $\left(3 \mathrm{Al}_{2} \mathrm{O}_{3} \cdot 2 \mathrm{SiO}_{2}\right)$ and $\gamma-\mathrm{Al}_{2} \mathrm{O}_{3}$ phases are present in all coatings. The coatings produced on $\mathrm{Al}-4 \mathrm{Mn}$ and $\mathrm{Al}-4 \mathrm{Mg}$ alloys additionally contain $\alpha-\mathrm{Al}_{2} \mathrm{O}_{3}$ phase. The intensity of peaks corresponding to $\alpha-\mathrm{Al}_{2} \mathrm{O}_{3}$ phase is higher for the coating produced on $\mathrm{Al}-4 \mathrm{Mn}$ alloy than the coating produced on Al-4Mg alloy. The hump formed on the XRD patterns of Al-4Si and Al-4Mn, which shows the existence of amorphous structure, was not evident on the $\mathrm{MAO}$ coating formed on $\mathrm{Al}-4 \mathrm{Mg}$.

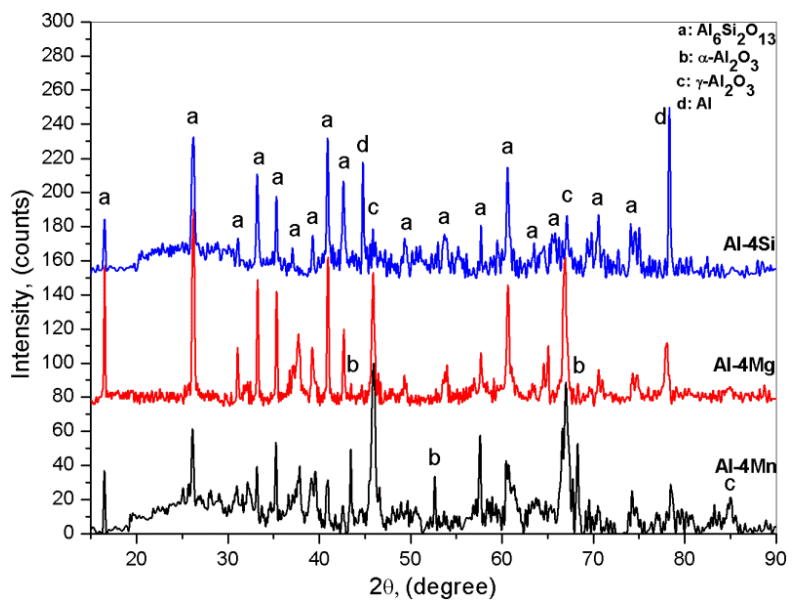

Fig. 1. XRD patterns obtained from the surface of MAO coating formed on $\mathrm{Al}-4 \mathrm{Mn}, \mathrm{Al}-4 \mathrm{Mg}$ and $\mathrm{Al}-4 \mathrm{Si}$ alloys.
The mullite phase forms as a result of the reaction among $\mathrm{Al}, \mathrm{Si}$ and $\mathrm{O}$. This reaction is enhanced by high $\mathrm{Si}$ concentration, which originated from the electrolyte, in the outer regions of coatings, and high local temperature and pressure, provided by micro-arcs. Rapid solidification of $\mathrm{Al}_{x} \mathrm{O}_{y}$ during the initial states of MAO process, due to the contact of cold solution to the coating surface, promotes $\gamma-\mathrm{Al}_{2} \mathrm{O}_{3}$ formation. During the coating process, presence of micro-arcs induces generation of local high temperatures, whereas slow cooling due to low thermal conductivity of the oxide coating, provides time for transformation of $\gamma-\mathrm{A}_{2} \mathrm{O}_{3}$ to $\alpha-\mathrm{A}_{2} \mathrm{O}_{3}$ and promotes $\alpha-\mathrm{A}_{2} \mathrm{O}_{3}$ formation in the inner region of the coating [4]. As it is well known, the metastable $\gamma-\mathrm{Al}_{2} \mathrm{O}_{3}$ phase transforms to $\alpha-\mathrm{Al}_{2} \mathrm{O}_{3}$ by heating to temperatures between $800{ }^{\circ} \mathrm{C}$ and $1200{ }^{\circ} \mathrm{C}$. Hence, the highest $\alpha-\mathrm{A}_{2} \mathrm{O}_{3}$ content in the coating is attributed to the thickest coating on Al-4Mn alloy (Fig. 4). The XRD patterns as well as the cross-sectional SEM micrographs show that the coating produced on $\mathrm{Al}-4 \mathrm{Si}$ alloy does not contain $\alpha-\mathrm{Al}_{2} \mathrm{O}_{3}$. The cross-section SEM micrographs also showed that the coating on Al-4Si alloy contains high amount of porosities and porosities with relatively big size. It is believed that high cooling rate through inner regions of coating, owing to the relatively low thickness of the coating, as well as penetration of cold electrolyte into coating through pores, prevents the transformation of $\gamma-\mathrm{Al}_{2} \mathrm{O}_{3}$ phase to $\alpha-\mathrm{Al}_{2} \mathrm{O}_{3}$ phase. Moreover, due to high amount of $\mathrm{Si}$ in the substrate, the concentration of $\mathrm{Si}$ in the transition layer of the coating increases, and this diminishes $\mathrm{Al}$ contribution to the further coating growth and consequently the formation of $\alpha-\mathrm{Al}_{2} \mathrm{O}_{3}$ [17]. This finding is parallel to the findings of similar studies, as it was reported in literature, that the coating thickness decreased with the increase of $\mathrm{Si}$ in the substrate [17]. It should be also noted that the intensity of XRD peaks belonging to the elemental $\mathrm{Al}$ originated from the substrate increases with the decreasing coating thickness.

Figure 2 illustrates surface roughness of the coatings and average thickness values determined from the crosssectional SEM micrographs. It can be seen that the coating on Al-4Mn alloys has the average coating thickness of approximately $127 \pm 11.58 \mu \mathrm{m}$. The average coating thicknesses formed on $\mathrm{Al}-4 \mathrm{Mg}$ and $\mathrm{Al}-4 \mathrm{Si}$ alloys are $91 \pm 4.30 \mu \mathrm{m}$ and $78 \pm 10.10 \mu \mathrm{m}$, respectively. The average surface roughness $(\mathrm{Ra})$ values are $10.20 \pm 2.28 \mu \mathrm{m}$, $8.86 \pm 0.75 \mu \mathrm{m}$ and $7.34 \pm 0.90 \mu \mathrm{m}$ for coatings formed on $\mathrm{Al}-4 \mathrm{Si}, \mathrm{Al}-4 \mathrm{Mg}$ and $\mathrm{Al}-4 \mathrm{Mn}$ alloys, respectively. The scattering is evident for all coatings tough it is maximum for the coating of Al-4Si alloy.

The results show that the highest thickness gain was obtained for coating on $\mathrm{Al}-4 \mathrm{Mn}$ alloy. It is thought that, manganese in substrate contributes to thickness gain by oxidizing and mixing into the coating structures, owing to its electrochemical activity and oxygen affinity, which is close to that of aluminum. Similarly, magnesium is also believed to enhance thickness gain on $\mathrm{Al}-4 \mathrm{Mg}$ alloy due to its very high oxidation tendency and rate $[3,18]$. The 

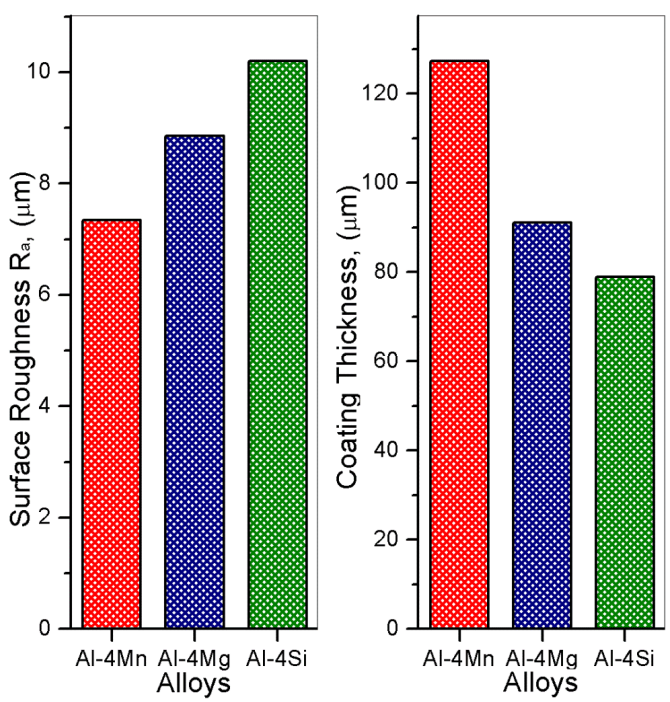

Fig. 2. The change in MAO coating thickness and surface roughness $\left(R_{a}\right)$ of coatings.

presence of manganese and magnesium was confirmed by the SEM-EDS results (Fig. 5). Moreover, high amount of porosity in coatings also promotes thickness gain, as it increases total volume of the coating though it reduces the theoretical density of the oxide layer formed. The surface and cross-sectional SEM micrographs together with XRD results revealed that the surface of coating produced on Al-4Si alloy is dominated by high amount of glassy structure. As MAO process progresses, this glassy layer cracks and come off due to intense arcs generating on the surface, which result in high surface roughness. It is presumed that this phenomenon as well as relatively lower affinity of Si toward oxygen, compared to Mn and $\mathrm{Mg}$, interrupt further oxidation and consequently limit the thickness gain [17]. High surface roughness of the MAO coatings is the result of transfer of molten materials from substrate to coating surface through discharge channels. Although the surface of coating on Al-4Si alloy appears relatively smooth, standard deviation of surface roughness measurements is relatively higher.

The surface SEM micrographs of MAO coated Al-4Si, Al-4Mg and Al-4Mn alloys are given in Fig. 3a, 3b and $3 c$, respectively. Spherical features, cracks, various sized pores as well as some hollow hemisphere shaped features can be seen on the surface of all coatings. The surface of the coating on Al-4Si alloy has a relatively smooth glassy appearance with some cracks. The molten material is carried to the coating surface through discharge channels from the inner region of the coating, contacts with cold electrolyte, solidifies and covers the surface to form these smooth and glassy regions $[19,20]$. It is believed that due to high $\mathrm{Si}$ content in the coating, a glassy $\mathrm{Si}_{x} \mathrm{O}_{y}$ structure forms on the surface of coating on Al-4Si alloy. The presence of the humpy regions on XRD patterns verifies the presence of an amorphous structure. The spherical and irregular shaped sponge-like structures and hollow hemi-

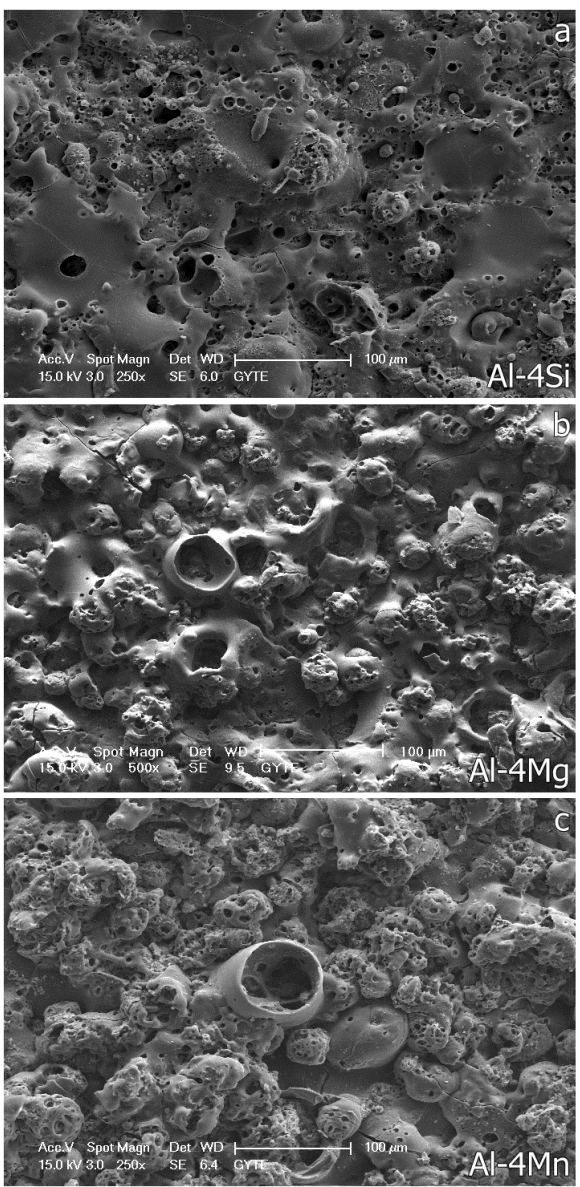

Fig. 3. The surface SEM micrographs of the MAO coated alloys: (a) Al-4Si, (b) Al-4Mg, (c) Al-4Mn.

sphere shaped features can be seen on the surface of the coatings of $\mathrm{Al}-4 \mathrm{Mg}$ and $\mathrm{Al}-4 \mathrm{Mn}$ alloys. These features form around the opening mouth of the plasma channels on the coating surface. The evaporated material reaching the coating surface through plasma channels cause formation of hollow bubbles with very thin wall thickness. These bubbles are cracked and formed hollow hemispherical structures due to rapid solidification and consequently thermal stresses which aroused from the local temperature difference between the coating and cold electrolyte. The formation of the pores is attributed to evaporation in coatings, which is a result of local high temperatures generated by plasma formation, while the formation of cracks is mainly a result of thermal stresses generated by high cooling rates on the surface of ceramic coatings and high local pressures created by material transfer through discharge channels [11].

The cross-sectional SEM images of MAO coated $\mathrm{Al}-4 \mathrm{Si}, \mathrm{Al}-4 \mathrm{Mg}$ and $\mathrm{Al}-4 \mathrm{Mn}$ alloys are shown in Fig. 4. The coatings are adhered to the substrates very well and the coating layer is labeled as three regions. The loose outer region (III) of the coatings contains high amount of large pores while the region on $\mathrm{Al}-4 \mathrm{Si}$ alloy has a glassy 

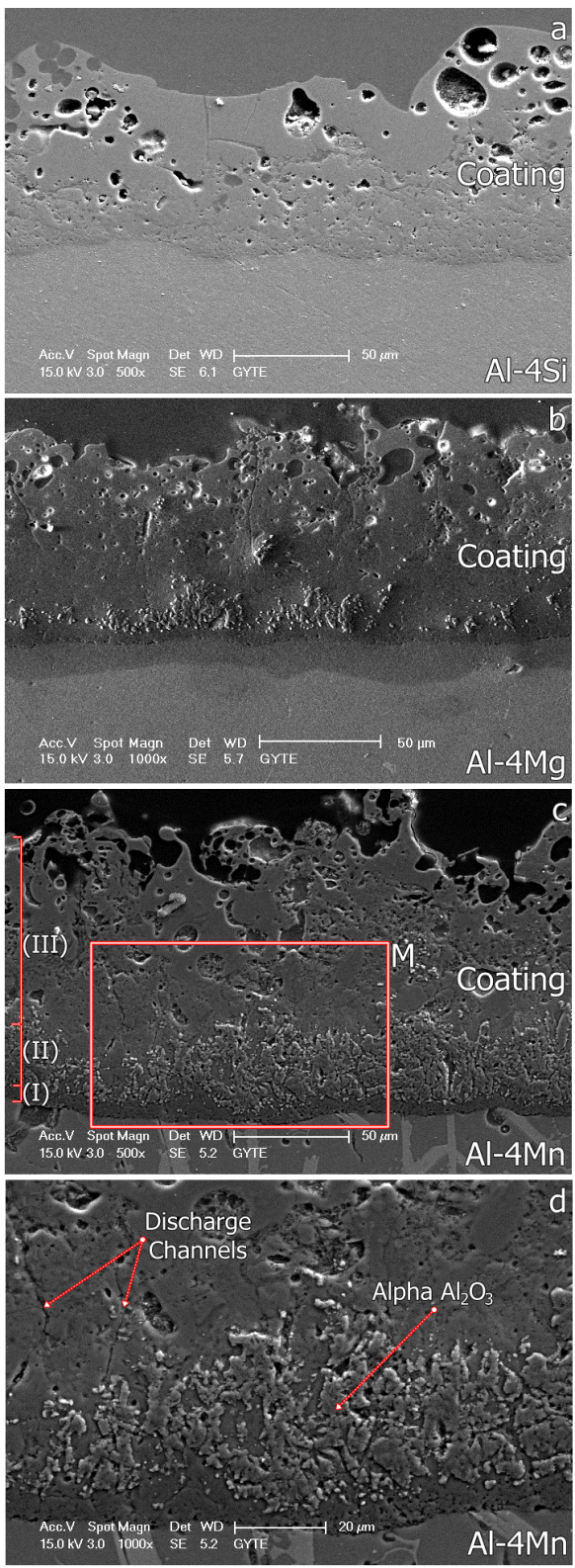

Fig. 4. The cross-sectional micrographs of the MAO coated Al alloys; (a) Al-4Si, (b) Al-4Mg, (c) Al-4Mn, (d) magnification of region " $M$ " in Fig. 4c.

appearance (Fig. 4a). The inner region (II) close to the substrate-coating interface of the coatings is relatively dense with small pores. The precipitates having irregular shapes are observed in the inner regions (II) of the coatings on Al-4Mg and Al-4Mn alloys (Fig. 4b, 4c). The precipitates, in the cross sectional micrograph of the coating of Al-4Mn (Fig. 4c), are more clearly seen in higher magnification cross-sectional micrograph (Fig. 4d). It was reported in similar studies on MAO coating of aluminum alloys that these precipitates are $\alpha-\mathrm{Al}_{2} \mathrm{O}_{3}[3,16]$. XRD results of this study also confirm that these precipitates are $\alpha-\mathrm{Al}_{2} \mathrm{O}_{3}$ particles (Fig. 1). The cross-sectional SEM micrographs show that $\alpha-\mathrm{Al}_{2} \mathrm{O}_{3}$ precipitates form a continuous band structure along the inner region of the coating on Al-4Mn alloy (Fig. 4c, 4d). However, the coating on $\mathrm{Al}-4 \mathrm{Mg}$ alloy contains fewer amounts of $\alpha$ $\mathrm{Al}_{2} \mathrm{O}_{3}$ precipitates with a relatively sparse distribution. On the other hand the coating produced on Al-4Si alloy does not contain any $\alpha-\mathrm{Al}_{2} \mathrm{O}_{3}$ precipitates. Figure 4 also shows that the discharge channels lying from substratecoating interface towards the coating surface (Fig. 4d). In addition to these regions II and III, a thin continuous region (I), with free from cracks and pores transition layer, close to the substrates, is seen from the micrographs of the coatings on $\mathrm{Al}-4 \mathrm{Si}, \mathrm{Al}-4 \mathrm{Mg}$ and $\mathrm{Al}-4 \mathrm{Mn}$ alloys.

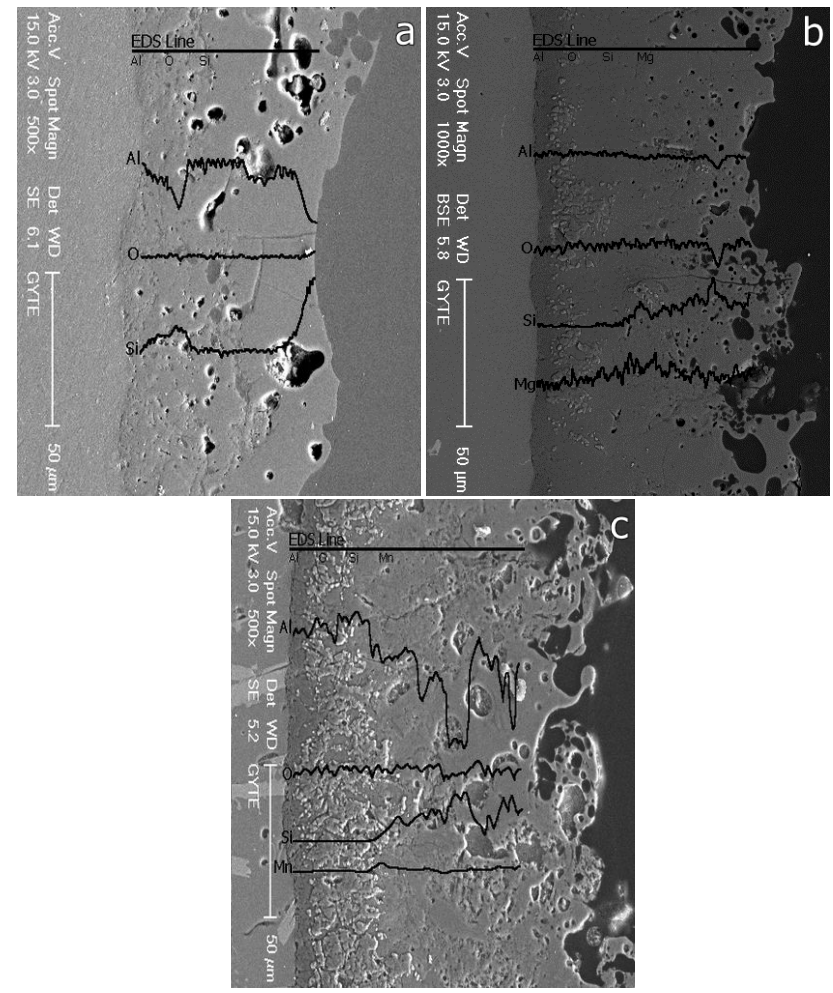

Fig. 5. The cross-sectional micrographs with a typical line SEM-EDS analysis results: (a) Al-4Si, (b) $\mathrm{Al}-4 \mathrm{Mg}$, (c) Al-4Mn.

Typical SEM-EDS line analysis results of the coatings on Al-4Si, Al-4Mg and Al-4Mn alloys on their crosssectional images are illustrated in Fig. 5a, 5b and 5c, respectively. The SEM-EDS spectra show that outer regions (III) of all coatings are rich in $\mathrm{Si}$. The presence of $\mathrm{Si}$ is also evident in region II, in the coating formed on Al-4Si alloy. Although both $\mathrm{O}$ and Si from electrolyte solution penetrate into the coating, $\left(\mathrm{SiO}_{3}\right)^{-2}$ ions cannot reach the inner regions of the coating. The concentration of oxygen is almost constant from the coating/substrate interface to surface of the coatings. The relative amount of $\mathrm{Al}$ is approximately constant in the coating on $\mathrm{Al}-4 \mathrm{Mg}$ alloy, while it slightly decreases in the outer loose regions of coatings on $\mathrm{Al}-4 \mathrm{Mg}$ and $\mathrm{Al}-4 \mathrm{Mn}$ alloys. $\mathrm{Mg}$ and $\mathrm{Mn}$ were also detected in coatings on $\mathrm{Al}-4 \mathrm{Mg}$ and $\mathrm{Al}-4 \mathrm{Mn}$ 
alloys, indicating that magnesium and manganese from the substrate incorporate into the coating structure. The presence of the Mn was almost constant while $\mathrm{Mg}$ was slightly increasing from the interface towards the surface in those coatings.

\section{Conclusion}

Synthetic binary $\mathrm{Al}-4 \mathrm{X}(\mathrm{X}=\mathrm{Si}, \mathrm{Mn}, \mathrm{Mg}$ ) alloys were prepared as substrate materials, coated by MAO method and characterized to compare effects of same amount (4 at.\%) of $\mathrm{Si}, \mathrm{Mn}$, and $\mathrm{Mg}$ on properties of MAO coatings. Following results were obtained:

- All MAO coatings contain mullite $\left(3 \mathrm{Al}_{2} \mathrm{O}_{3} \cdot 2 \mathrm{SiO}_{2}\right)$ and $\gamma-\mathrm{Al}_{2} \mathrm{O}_{3}$ phases. In addition to these phases, $\alpha-\mathrm{Al}_{2} \mathrm{O}_{3}$ phase was formed in the MAO coatings of $\mathrm{Al}-4 \mathrm{Mn}$ and $\mathrm{Al}-4 \mathrm{Mg}$ alloys.

- The average coating thicknesses are $127 \mu \mathrm{m}, 91 \mu \mathrm{m}$ and $78 \mu \mathrm{m}$ on Al-4Mn, Al-4Mg and Al-4Si alloys, respectively.

- The average surface roughness (Ra) values are $10.20 \mu \mathrm{m}, 8.86 \mu \mathrm{m}$ and $7.34 \mu \mathrm{m}$ for the coatings on $\mathrm{Al}-4 \mathrm{Si}, \mathrm{Al}-4 \mathrm{Mg}$ and $\mathrm{Al}-4 \mathrm{Mn}$ alloys, respectively.

- Spherical features, cracks, various sized pores and discharge channels can be seen on the surface of all coatings. Surface of coating produced on Al$4 \mathrm{Si}$ alloy is dominated by high amount of glassy structure, whereas surfaces of coatings on Al-4Mn and $\mathrm{Al}-4 \mathrm{Mg}$ alloys contain large amount of spongelike coarse features.

- The coatings are composed of three main regions. The outer region is a loose layer with large porosities. The outer region of the coating produced on Al-4Si alloy is composed of a glassy amorphous structure. The inner region close to substrate/coating interface of coatings is relatively dense, with $\alpha-\mathrm{A}_{2} \mathrm{O}_{3}$ precipitates distributed in the form of band in the coatings of Al-4Mg and Al-4Mn alloys. The third region is the thin transition layer, closest to the substrate/coating interface.

- Al, Si and O are present in all coatings. Additionally, $\mathrm{Mn}$ and $\mathrm{Mg}$ exist in the coating produced on Al-4Mn and Al-4Mg alloy respectively. The outer regions of all coatings and the inner region of the coating on Al-4Si alloy are rich in $\mathrm{Si}$.

\section{References}

[1] H.Y. Ding, Z.D. Dai, S.C. Skuiry, D. Hui, Tribol. Int. 43, 868 (2010).

[2] F.T. Xu, Y. Xia, G. Li, Appl. Surf. Sci. 255, 9531 (2009).

[3] M. Tarakci, Mater. Charact. 62, 1214 (2011).

[4] L.R. Krishna, A.S. Purnima, N.P. Wasekar, G. Sundararajan, Metall. Mater. Trans. A 38, 370 (2007).

[5] Y. Ma, X. Zhou, G.E. Thompson, M. Curioni, T. Hashimoto, P. Skeldon, P. Thomson, M. Fowles, J. Electrochem. Soc. 158, C17 (2011).

[6] M. Yoshimoto, Y. Morizono, S. Tsurekawa, T. Baba, J. Ceram. Soc. Jpn. 120, 276 (2012).

[7] X. Nie, A. Leyland, H.W. Song, A.L. Yerokhin, S.J. Dowey, A. Matthews, Surf. Coat. Tech. 116119, 1055 (1999).

[8] C.E. Barchiche, E. Rocca, C. Juers, J. Hazan, J. Steinmetz, Electrochim. Acta 53, 417 (2007).

[9] G.H. Lv, H. Chen, L. Li, E.W. Niu, H. Pang, B. Zou, S.Z. Yang, Curr. Appl. Phys. 9, 126 (2009).

[10] W. Shang, B.Z. Chen, X.C. Shi, Y. Chen, X. Xiao, J. Alloy. Compd. 474, 541 (2009).

[11] E. Matykina, R. Arrabal, P. Skeldon, G.E. Thompson, P. Wang, P. Wood, Surf. Coat. Tech. 204, 2142 (2010).

[12] F. Liu, J.L. Xu, D.Z. Yu, F.P. Wang, L.C. Zhao, Mater. Chem. Phys. 121, 172 (2010).

[13] A.L. Yerokhin, X. Nie, A. Leyland, A. Matthews, S.J. Dowey, Surf. Coat. Tech. 122, 73 (1999).

[14] W.B. Xue, Z.W. Deng, Y.C. Lai, R.Y. Chen, J. Am. Ceram. Soc. 81, 1365 (1998).

[15] Y. Gencer, M. Tarakci, A.E. Gulec, Z.C. Oter, Acta Phys. Pol. A 125, 659 (2014).

[16] Y. Gencer, A.E. Gulec, J. Alloy. Compd. 525, 159 (2012).

[17] A.E. Gulec, M.Sc. Thesis, Sentetik Al-Si Ikili Alaşımlarının Mikro Ark Oksidasyon (MAO) Tekniği ile Kaplanması, Materials Science and Engineering, Gebze Institute of Technology, Gebze, Kocaeli, Turkey 2012.

[18] Z.C. Oter, M.Sc. Thesis, Sentetik Al-Mn Alaşımlarının Mikro Ark Oksidasyon Tekniği ile Kaplanması, Materials Science and Engineering, Gebze Institute of Technology, Gebze, Kocaeli, Turkey (2013).

[19] G. Sundararajan, L.R. Krishna, Surf. Coat. Tech. 167, 269 (2003).

[20] R.O. Hussein, X. Nie, D.O. Northwood, Surf. Coat. Tech. 205, 1659 (2010). 